\title{
APPLICATION OF GAME THEORY FOR DUOPOLY MARKET ANALYSIS
}

\author{
Romualdas Ginevičius $^{1}$, Algirdas Krivka² \\ Vilnius Gediminas Technical University, Department of Economics and Management of Enterprises, \\ Saulètekio al. 11, LT-10223 Vilnius, Lithuania

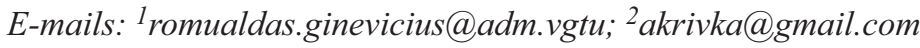 \\ Received 18 September 2007; accepted 5 May 2008
}

\begin{abstract}
The paper provides the analysis of game theory models application to identify duopoly market equilibrium (quantities sold and market prices), to evaluate and compare the results of enterprises in a market. The purpose of the analysis is to determine to what extent theoretical models correspond to real life, that is how reliable they are in supporting and estimating decisions of duopoly companies, fortifying market prices and quantities sold, evaluating company's competing positions and possibilities for decision co-ordination. To describe discrete strategies equilibrium the "Prisoner's Dilemma" model is applied to a hypothetic market entrance game with possible side payments. Further analysis of the market entrance game incorporates mixed strategies based "Matching Pennies" model in case discrete strategies equilibrium does not exist. Continuous strategies are described analyzing hypothetic duopoly by applying Cournot, Stackelberg and Bertrand models. The first and the second mover advantage issues are raised comparing outcomes of dynamic Stackelberg and Bertrand games for a leader and a follower. Stability and utility of cartel agreement for its participants is mathematically supported with the help of a multi-step repeated Cournot game. Having described, compared and applied the main game theory models to artificial duopoly market situations, the author passes over to the comparative analysis of the models' weaknesses and problems related to their practical application.
\end{abstract}

Keywords: oligopoly, duopoly, game theory, discrete strategies, mixed strategies, Cournot, Bertrand.

\section{Introduction}

Among all classic market structure models (pure competition, monopoly, oligopoly and monopolistic competition) oligopoly models are the ones that attract the most of scientists' attention in recent years. On the one hand that is due to the spread and importance of oligopoly markets in modern economy (for example, food product markets, drugs market, beer and light alcohol market, cell phone services market and some others may be considered oligopolies in Lithuania); on the other hand, analysis of oligopoly markets is probably the most difficult of all market structures. The importance of interaction of market participants is the main factor distinguishing oligopoly market from other non-perfect competition market structures, because actions of any market player (the choice of prices and quantities to be produced) directly affect market equilibrium and indirectly - the results of all competitors. Increase in seller concentration tends to raise industrywide markups and profitability by facilitating collusion (Ponikvar, Rant 2007), thus oligopoly markets also earn the special attention of government antitrust services - oligopoly is traditionally characterized by a higher possibility of producers' collusive agreements, market dominance discrimination and other variations of unfair competition.

Duopoly is a form of oligopoly market having two participants only: producers or sellers. As the number of competitors is limited to just two, their interaction becomes even more important. Every producer, before making decisions on prices and quantities, has to take into account not only the current strategy of the competitor, but his forthcoming responsive actions as well. Besides, the case of only two players in a market raises the chances for non-competitive agreements - probably, it is not complicated for two producers to coordinate their actions and monitor the implementation of the agreement. In such case monopolistic pricing would prevail, creating extremely unfavourable conditions for consumers.

The most famous oligopoly models were designed in the $19^{\text {th }}$ century. A well known French mathematician, philosopher and economist A. Cournot in his book of 1838, named "Researches into the Mathematical Prin- 
ciples of the Theory of Wealth", applies mathematical models for analyzing market demand and production costs, provides profit maximization conditions for different types of market structures and presents the classic duopoly model, named in his honour. The author of another famous oligopoly model is a French scientist as well $-\mathrm{J}$. Bertrand, who presented the model of price competition in a duopoly market in 1883 . The works of A. Cournot were continued by a German economist H. Von Stackelberg, who designed the quantity leadership model in 1934. Later on, as the science of industrial organization gained its popularity, mathematical methods, especially game theory, proved to be the mainstream in analyzing oligopoly markets. A Hungarian mathematician J. Von Neumann and Austrian economist $\mathrm{O}$. Morgenstern are considered to be the originators of game theory, releasing their main proceedings, named "Theory of Games and Economic Behaviour", in 1944.

Nowadays, in works of both Lithuanian and foreign scientists, it has become common for game theory to be presented as the most efficient tool for oligopoly market research; although such opinion obviously lacks critical evaluation of game theory's practical application. The game theory approach is usually limited to designing a complicated multi-variable mathematical model, which leads to purely theoretical conclusions based on multiple assumptions, without deepening into possibilities to apply the model in practice. The author of the article aims to fill up this niche, suggesting his grounded opinion on practical application of game theory in duopoly market research.

The paper reviews the main game theory models commonly applied to analyze duopoly markets: the models are employed to estimate market equilibrium, to evaluate gains and losses of each market player and the efficiency of equilibrium at the industry level; raises the issue of equilibrium stability. It is endeavoured to provide a balanced and reasonable opinion, to what extent theoretical results correspond to reality - that is how appropriate game theory is for analyzing actions of real enterprises. To support the author's conclusions, the comparative analysis of classic duopoly models on the issue of their practical application is implemented. The problem of the article is the practical application of game theory models to analyze a real duopoly market. The aim of research is, by examining the classic game theory models, to evaluate validity and benefits of application of game theory for estimating equilibrium in a duopoly market.

The object of the research is the game theory models traditionally applied for duopoly market analysis. The research methods are the systematic science literature analysis and the comparative analysis of the theoretical models. The paper is based on the works of J. Von Neumann and O. Morgenstern, K. Aiginger, J. Friedman, E. Rasmusen, D. Carlton and J. Perloff, M. Jackson and S. Wilkie and other authors, having considerable contribution to the development of game theory and its application. The technique of applying theoretical models to hypothetic market situations accompanied by non-complicated mathematical calculations is used in the article to support the author's arguments and conclusions.

\section{The application of discrete and mixed strategies}

In case of discrete strategies the action set of every duopoly market participant (they are called players) is composed of several alternative strategic decisions. For example, a large cell phone services providing enterprise is pondering upon entering a monopolistic market of stationary (wire line) phone services, making the decision enter or stay out. It is absolutely natural that the incumbent would react to any decision of the entrant, or even to a credibly expressed intention to make one or another decision. The decisions of the monopolist in such case could be give up, i. e. not to resist the entrance of the newcomer, or compete - to cut prices (also experiencing a drop in profit) in order to extrude the competitor. The incumbent might attempt to outrun the entrant - to announce earnestly (credibly) about the intention to compete before the newcomer makes the decision on entry. For example, the monopolist could officially announce about the large scale longterm investment aiming to improve quality of services and reduce their costs, thus confirming the intention to dominate the market and deterring the entrance.

A classic discrete strategies model is called the "Prisoner's Dilemma". The author of the article proposes to reformulate the classic model (Skinner, Chamberlin 2001; Rasmusen 2006), describing the actions of two prisoners interrogated separately, each choosing from the action set (confess, deny), but to maintain the rules of the "Prisoner's Dilemma", i. e. the game is static (played only once), moves are simultaneous, information is imperfect symmetrical - players cannot communicate. The payoff matrix (Table 1) shows the possible combinations of players' actions and expected payoffs (profits).

The problem might be solved rather easily with the iterated dominance technique: the incumbent has a strictly dominant strategy give up, the newcomer would then choose enter. The equilibrium strategy profile is (enter, 
give up), while the payoffs are $\left(\pi_{1} ; \pi_{2}\right)=(200 ; 200)$. The discovered strategy profile is Nash equilibrium an outcome, from which neither player would like to deviate if other players do not deviate either; besides, Nash equilibrium in this model is unique. It also has to be noted that the equilibrium strategy profile would not have changed if the game was played step-by-step. For the model to be more adequate to reality it is worth laying aside one more assumption -players are allowed to communicate and make mandatory (compulsory) agreements. The logic of such agreements from theoretical side is supported by Pareto efficiency condition, which maximizes the total profit of two enterprises, while from practical side it is encouraged by the natural intention of any rationally acting producer to maximise his own profit. Maximum total profit of $\pi_{1}+\pi_{2}=500$ is achieved with the strategy profile (stay out, give up). The incumbent could offer to share monopolistic profit with the newcomer if the latter agrees not to enter. The newcomer could expect to receive a side payment (compensation) of $[200 ; 300]$, with the exact amount to be the subject of negotiations (Table 2).

Table 1. The entrance game payoff matrix

\begin{tabular}{cccc}
\hline & \multicolumn{2}{c}{ Incumbent } \\
\hline & & Compete & Give up \\
\cline { 2 - 3 } 泀 & Enter & $-20 ; 100$ & $\mathbf{2 0 0} ; \mathbf{2 0 0}$ \\
\cline { 2 - 3 } & Stay out & $0 ; 150$ & $0 ; 500$ \\
\hline
\end{tabular}

Payoffs: (Entrant; Incumbent)

Table 2. The entrance with side payments game payoff matrix

\begin{tabular}{|c|c|c|c|}
\hline & & \multicolumn{2}{|c|}{ Incumbent } \\
\hline \multirow{3}{*}{ 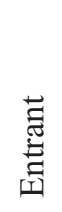 } & & Compete & Give up \\
\hline & Enter & $-20 ; 100$ & $200 ; 200$ \\
\hline & Stay out & $\begin{array}{l}{[200 ; 300] ;} \\
{[-150 ;-50]}\end{array}$ & $\begin{array}{l}{[200 ; 300] ;} \\
{[200 ; 300]}\end{array}$ \\
\hline
\end{tabular}

Payoffs: (Entrant; Incumbent)

The equilibrium results from the strictly dominant incumbent's strategy give up and the entrant's weakly dominant stay out. However, side payments are not a universal solution in drifting to efficient strategy profile. M. Jackson and S. Wilkie (2000) prove that equilibrium outcomes of games, having free pre-game side payment agreements, cannot be considered as always efficient. Moreover, according to M. Jackson and S. Wilkie, side payment agreements may result in ineffi- cient outcomes in games, having efficient equilibriums without such agreements.

In the examples above the estimated equilibriums were unique. However, a game may have several Nash equilibriums or even none of them. In such cases the mixed strategies approach could be applied.

A mixed strategy maps each of the player's possible information sets to a probability distribution over actions $-s_{i}: w_{i} \rightarrow m\left(a_{i}\right)$, where $m \geq 0$ and $\int m\left(a_{i}\right) d a_{i}=1$ (Rasmusen 2006). To characterize mixed strategies another market entrance game is analyzed. Two enterprises: the medium (m) and the large (l) - play a market entrance game with the following action sets: $S_{m}=\left\{\right.$ enter the $1^{\text {st }}$ market; stay out $\}, S_{l}=\{$ enter the $1^{\text {st }}$ market only; enter both markets $\}$. The medium enterprise is unable to enter both markets (lacks investment funds), while the large one can enter either the $1^{\text {st }}$ market only or both markets. The $1^{\text {st }}$ market, for example, could be a wholesale oil market, the $2^{\text {nd }}$ one - a retail petrol market. As previously, the payoff matrix is drawn in order to estimate the equilibrium (Table 3).

Table 3. The mixed strategies game payoff matrix

\begin{tabular}{|c|c|c|c|}
\hline & & \multicolumn{2}{|c|}{ Large } \\
\hline \multirow{3}{*}{ 莺 } & & $\begin{array}{c}\text { Enter the } 1^{\text {st }} \\
\text { only }(\theta)\end{array}$ & $\begin{array}{l}\text { Enter both } \\
\quad(1-\theta)\end{array}$ \\
\hline & Enter the $1^{\text {st }}(\omega)$ & $-100 ; 400$ & $400 ; 300$ \\
\hline & Stay out $(1-\omega)$ & $0 ; 600$ & $0 ; 1000$ \\
\hline
\end{tabular}

Payoffs: $\left(\pi_{m} ; \pi_{l}\right)$

The players have no dominant strategies, there is no pure strategies Nash equilibrium in the model. If both enterprises enter the $1^{\text {st }}$ market, the large company easily extrudes the medium one; in case the medium stays out, the large prefers to enter both markets; then for the medium enterprise it is worth entering the $1^{\text {st }}$ market because the large one, having superior but in any case limited resources, would be beaten in the $1^{\text {st }}$ market (its payoff is positive due to the $2^{\text {nd }}$ market profit only); that brings it back to the outcome with both companies in the $1^{\text {st }}$ market. The composed model, having no pure strategies equilibrium, is similar to the classic "Matching-Pennies" model (Von Neumann, Morgenstern 1953).

In order to find the equilibrium, mixed strategies are applied. Denote the probability the medium company enters the $1^{\text {st }}$ market by $\omega$, the probability the large one enters the $1^{\text {st }}$ market only by $\theta$. Then the medium 
enterprise stays out with the probability $1-\omega$, while the large enters both markets with the probability $1-\theta$. The expected profit of the medium company is:

$\pi_{m}=\omega(-100 \theta+400(1-\theta))+(1-\omega)(0 \theta+0(1-\theta))=$ $\omega(400-500 \theta)$.

$\pi_{m}(\omega)$ maximization gives the result of $\theta=0.8-$ the probability (that the large company enters the $1^{\text {st }}$ market only) that makes the medium enterprise indifferent while choosing among its actions. This probability might have been calculated in another way - by equalling expected payoffs of the medium company choosing its action from \{enter the $1^{\text {st }}$ market; stay out\}, while these payoffs depend on the large company's probability of actions:

$$
-100 \theta+400(1-\theta)=0 \theta+0(1-\theta) \Rightarrow \theta=0.8 .
$$

Be the probability $\theta>0.8$, the expected payoff of the medium enterprise from enter the $1^{\text {st }}$ market would be less than from stay out, so the company would have the dominant pure strategy stay out. According to the calculations, if the large company manages to assure the probability $\theta>0.8$ that it chooses the $1^{\text {st }}$ market only (for example, running open and public negotiations with the government on privatization of a pipeline and, at the same time, drawing the curtain on agreement to purchase a large network of petrol stations), it may achieve the favourable outcome \{stay out; enter both markets\}. However, that would be the pure strategies equilibrium. Coming back to mixed strategies, the probability $\omega$ is calculated in the similar way:

$400 \omega+600(1-\omega)=300 \omega+1000(1-\omega) \Rightarrow \omega=0.8$.

The medium enterprise enters the $1^{\text {st }}$ market with the probability $\omega=0.8$. Mixed strategies equilibrium exists for the medium company to choose enter the $1^{\text {st }}$ market with the probability $\omega=0.8$ and for the large to choose enter the $1^{\text {st }}$ market only with the equal probability $\theta=0.8$. Any possible strategy profile might be the equilibrium but the most expected is \{enter the $1^{\text {st }}$ market; enter the $1^{\text {st }}$ market only $\}$ (the probability is $0.64=0.8 \times 0.8)$.

Nevertheless the mixed strategies approach allows estimating Nash equilibrium when pure strategies seem to be fruitless, the application of mixed strategies is limited due to the following aspects (Rasmusen 2006):

1. Real world companies usually do not make random decisions. This argument is not convincing enough because a mixed strategies model is a good reflection of the world where observers treat events and surrounding environment as random and accidental.
2. A more important argument is that a player, choosing a mixed strategy, is always indifferent among several pure strategies. Mixed strategies Nash equilibrium is always weak being the case when a player picks one of equally good (and equally bad) alternative strategies.

\section{The analysis of simultaneous Cournot equilibrium}

Until this part of the article the analysis touched upon discrete strategies: enter the market, stay out, compete, give up, etc. Sometimes, in case of pure strategies and simultaneous moves, equilibrium does not exist. Mixed strategies offer a "compromise", for example enter a market with the certain probability. From now on continuous strategies - meaning that player's action set is an interval of certain action - are used to estimate equilibrium in duopoly markets. Cournot duopoly players choose quantities (outputs) of homogeneous products simultaneously without communication. There are two producers only, each of them being large enough for a change of his output to affect market price, which in turn affects profits of both producers.

Market demand could be expressed as $p\left(q_{1}, q_{2}\right)=a-$ $q_{1}-q_{2}$, where $q_{1}, q_{2} \in[0 ; a)$ are companies' outputs (assuming, each enterprise can fill the whole market), $a-$ a positive constant.

Denote variable costs by $c$ (with fixed costs, having no impact on the optimal output, being zero). The profit functions would be:

$$
\begin{aligned}
& \pi_{1}=\left(a-q_{1}-q_{2}\right) q_{1}-c q_{1} ; \\
& \pi_{2}=\left(a-q_{1}-q_{2}\right) q_{2}-c q_{2} .
\end{aligned}
$$

The solution for profit maximizing outputs is:

$$
\left\{\begin{array} { l } 
{ \frac { d \pi _ { 1 } } { d q _ { 1 } } = a - 2 q _ { 1 } - q _ { 2 } - c = 0 , } \\
{ \frac { d \pi _ { 2 } } { d q _ { 2 } } = a - 2 q _ { 2 } - q _ { 1 } - c = 0 , }
\end{array} \left\{\begin{array}{l}
q_{1}\left(q_{2}\right)=\frac{a-c-q_{2}}{2}, \\
q_{2}\left(q_{1}\right)=\frac{a-c-q_{1}}{2}
\end{array}\right.\right.
$$

- the best response or the reaction functions. The Cournot outputs $q_{1 c}, q_{2 c}$, the price $p_{c}$ and the profits $\pi_{1 c}, \pi_{2 c}$ are:

$$
q_{1 c}=q_{2 c}=\frac{a-c}{3} ; p_{c}=\frac{a+2 c}{3} ; \pi_{1 c}=\pi_{2 c}=\frac{(a-c)^{2}}{9} \text {. }
$$

The outputs calculated $\left(q_{1 c}, q_{2 c}\right)$ are the Cournot game Nash equilibrium, from which neither player would like to deviate. The quantities produced are not Pareto efficient (here and further in the article Pareto efficiency is considered from producer's point of view, 
leaving aside consumer surplus maximizing condition of $p=c$ ), meaning that, nevertheless the equilibrium outputs maximize the profit of each enterprise, they do not ensure the maximum total industry profit. The efficient output level for producers would be a monopoly output, maximum industry profit - monopoly profit:

$$
\pi_{M}=\left(a-q_{M}\right) q_{M}-c q_{M}
$$

The monopoly quantity $q_{M}$, the price $p_{M}$ and the profit $\pi_{M}$ are:

$$
q_{M}=\frac{a-c}{2} ; p_{M}=\frac{a+c}{2} ; \pi_{M}=\frac{(a-c)^{2}}{4} .
$$

The calculations confirm that instead of competing the companies could collude (make a cartel agreement) and, by maximizing the total industry net income, each achieve higher profit than in Cournot competition. The exact amount of profit of each enterprise is the subject of negotiations but, anyway, it should be in the following interval:

$$
\begin{gathered}
\frac{8}{72}(a-c)^{2} \leq \pi_{1 M}, \pi_{2 M} \leq \frac{10}{72}(a-c)^{2}, \text { where } \\
\pi_{1 M}+\pi_{2 M}=\frac{(a-c)^{2}}{4} .
\end{gathered}
$$

Unlike Cournot quantities, the shared cartel output is not steady equilibrium. It seems logical to raise the question, whether two companies, playing a simultaneous coordinated Cournot game, could ever reach a Pareto efficient outcome. Suppose the companies agree that each produces half monopoly output, so the monopoly profit is equally shared among the players:

$$
\begin{gathered}
q_{1 M}=q_{2 M}=\frac{1}{2} q_{M}=\frac{a-c}{4} ; \\
\pi_{1 M}=\pi_{2 M}=\frac{1}{2} \pi_{M}=\frac{(a-c)^{2}}{8} .
\end{gathered}
$$

However, the outputs $q_{1 M}=q_{2 M}=\frac{a-c}{4}$ are not on the players' best response functions. If the $2^{\text {nd }}$ company fairly follows the agreement, producing half monopoly output $\bar{q}_{2}=\frac{a-c}{4}$, the $1^{\text {st }}$ one tends to cheat producing:

$$
q_{1 s}\left(\bar{q}_{2}\right)=\frac{1}{2} \cdot\left(a-c-\frac{a-c}{4}\right)=\frac{3}{8}(a-c),
$$

where index $s$ means cheating. The profit of the $1^{\text {st }}$ enterprise exceeds its share of profit under the cartel:

$$
\pi_{1 s}\left(q_{1 s}, \bar{q}_{2}\right)=\frac{9}{64}(a-c)^{2},
$$

while the $2^{\text {nd }}$ company, following the agreement, worsens its result:

$$
\pi_{2}\left(q_{1 s}, \bar{q}_{2}\right)=\frac{3}{32}(a-c)^{2} .
$$

Assuming that each company has the same treatment of the situation in the market, it could be presumed that each player tends to cheat. In such case the profits would be equally small:

$$
\pi_{1 s}\left(q_{1 s}, q_{2 s}\right)=\pi_{2 s}\left(q_{1 s}, q_{2 s}\right)=\frac{3}{32}(a-c)^{2} .
$$

Natural will to cheat might be explained not by the best response functions only, but also by the cheater's impunity. The game is static and simultaneous, so a cheater takes extra profit and leaves unpunished.

The cheating example supports stability of CournotNash equilibrium once again. To summarize the executed calculations, the following two-step game is designed: first Cournot duopolists choose, whether to form a cartel; then each of them simultaneously chooses its output. Figure 1 represents the game in a form of a diagram (for the purpose of simplicity $(a-c)^{2}$ is equalled to 1$)$.

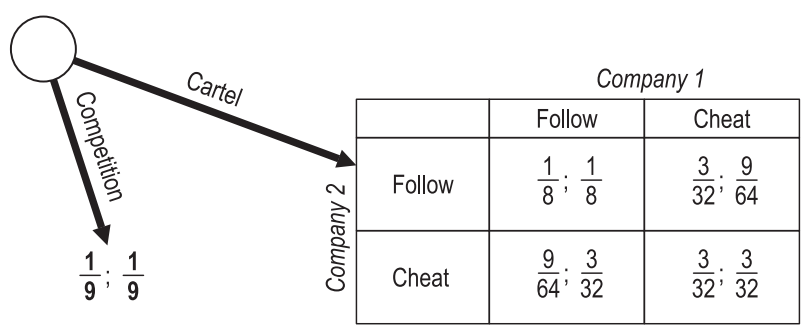

Fig. 1. The cheater's game scheme

It looks absolutely clear that Cheat is a weakly dominant strategy for each player, and $\{$ Cheat, Cheat $\}$ is the pure strategies Nash equilibrium. So, even if a pre-game cartel agreement in a simultaneous Cournot game exists, both companies would produce CournotNash equilibrium outputs (which are on their reaction functions). In such cases Cournot competitive quantities is the only possible outcome. Such conclusion supports stability of Cournot-Nash equilibrium, denying possibilities of cartel agreements in simultaneous static games.

\section{The first and the second mover advantage}

In Cournot game both producers choose their outputs simultaneously. If one of them could outrun his competitor and become the first to credibly announce the planned output, a game would become dynamic Stackelberg game. The game would be of two stages: first, a Stackelberg leader chooses his output, and then a Stackelberg follower, having all the information on 
the leader's choice at his disposal, makes the decision on his quantity (a perfect information game).

Assume, duopoly market conditions being the same as in the Cournot game analyzed in section 3, but the $1^{\text {st }}$ enterprise succeeds to credibly announce its output, thus becoming the Stackelberg leader. Estimation of the equilibrium starts from the follower's profit maximization problem, with the $2^{\text {nd }}$ company's reaction function $q_{2}\left(q_{1}\right)=\frac{a-c-q_{1}}{2}$ being its solution. The profit maximizing condition for the $1^{\text {st }}$ enterprise is:

$$
\frac{d \pi_{1}}{d q_{1}}=\left(a-q_{1}-\frac{a-c-q_{1}}{2}\right) q_{1}-c q_{1}=0 .
$$

Then $q_{1}=\frac{a-c}{2}$ is the output of the Stackelberg leader (it is purely accidental that the leader's quantity produced equals the monopolistic output) and $q_{2}\left(q_{1}\right)=\frac{a-c}{4}$ is
the follower's output.

It is worth emphasizing that estimated output levels are on both companies' reaction functions, thus supporting stability of the equilibrium. As neither producer would deviate from his output, the continuous strategies profile $\left(q_{1}, q_{2}\right)=\left(\frac{a-c}{2}, \frac{a-c}{4}\right)$ is the Stackelberg game Nash equilibrium. The mathematical expressions of the companies' profits prove the first mover advantage:

$$
\pi_{1}=\frac{(a-c)^{2}}{8} ; \pi_{2}=\frac{(a-c)^{2}}{16} .
$$

The Stackelberg leader in this case could expect twice larger profit than the follower. This conclusion corresponds to the real world principle that the first move usually gives an advantage in competitive interaction. However, game theory states that the first move leads to competitive advantage due to the negative slope of the best response curves. If the slope was positive, an advantage would arise from the second move. An example of the latter case is Bertrand model with differentiated products.

In the classic Bertrand gameproducers (or sellers) compete by choosing prices. As the products assumed to be absolutely identical (with additional assumptions on perfect information about prices, zero transportation costs and unlimited production capacity), the one, setting the lower price, possesses all the market. However, in case production is differentiated, demand is not absolutely elastic, allowing producers to raise prices above marginal costs without losing all consumers. Individual demand of a producer could be written as:

$$
q_{i}=A_{i}-a_{i} p_{i}+\sum_{\substack{j=1, j \neq i}}^{n} b_{i j} p_{j} .
$$

To simplify the model, assume, marginal costs of each enterprise are zero, as well as fixed costs, maximum potential individual demand is $A$, parameters ${ }^{a_{i}}$ are equal to 1 . First the simultaneous game with price variables and differentiated production is described, then it is passed over to the two-stage price setting model. The individual demand functions of the companies in the simultaneous differentiated Bertrand model are:

$$
\begin{aligned}
& q_{1}\left(p_{1}, p_{2}\right)=A-p_{1}+b_{2} p_{2} ; \\
& q_{2}\left(p_{1}, p_{2}\right)=A-p_{2}+b_{1} p_{1} ;
\end{aligned}
$$

while the profit expressions are:

$$
\begin{aligned}
& \pi_{1}\left(p_{1}, p_{2}\right)=p_{1}\left(A-p_{1}+b_{2} p_{2}\right) \\
& \pi_{2}\left(p_{1}, p_{2}\right)=p_{2}\left(A-p_{2}+b_{1} p_{1}\right) .
\end{aligned}
$$

The enterprises choose their prices simultaneously, in attempt to maximize their own profit, taking into account the expected competitor's choice. For parameters $b_{1}, b_{2}$ the condition of $0<b_{1}, b_{2}<1$ should be respected. If the latter parameters were zero, the products would be absolutely differentiated (monopolistic); in case the parameters were equal to or exceeded 1 , each company would be able to infinitely raise its price (growing price would not reduce its individual demand). Similar to Cournot, the system of two equations is solved to estimate the equilibrium, while the variables are not quantities, but prices $\left(p_{1}, p_{2}\right)$ :

$$
\left\{\begin{array}{l}
p_{1}\left(p_{2}\right)=\frac{1}{2}\left(A+b_{2} p_{2}\right) \\
p_{2}\left(p_{1}\right)=\frac{1}{2}\left(A+b_{1} p_{1}\right)
\end{array}-\right.\text { the best response functions. }
$$

Unlike Cournot quantity competition model, the slope of the best response curves is positive. Profit maximizing behaviour of a company, acting in Bertrand competition with differentiated production, in response to a competitor's price increase would be an increase in its own price. The prices would stand at:

$$
p_{1}^{*}=\frac{A\left(2+b_{2}\right)}{4-b_{1} b_{2}}, p_{2}^{*}=\frac{A\left(2+b_{1}\right)}{4-b_{1} b_{2}} .
$$

Attention should be drawn to the fact that the prices are positive, so they exceed [zero] marginal costs. Unlike the classic Bertrand model, the prices are higher than pure competitive, so both enterprises have market power. The economic profits would also be positive:

$$
\begin{aligned}
& \pi_{1}^{*}=p_{1}^{*}\left(A-p_{1}^{*}+b_{2} p_{2}^{*}\right)=\frac{A^{2}\left(2+b_{2}\right)^{2}}{\left(4-b_{1} b_{2}\right)^{2}} \\
& \pi_{2}^{*}=p_{2}^{*}\left(A-p_{2}^{*}+b_{1} p_{1}^{*}\right)=\frac{A^{2}\left(2+b_{1}\right)^{2}}{\left(4-b_{1} b_{2}\right)^{2}} .
\end{aligned}
$$


The mathematical analysis of differentiated Bertrand shows that in case of price competition and product differentiation, both players possess market power, so production prices stand above marginal costs, while producers gain economic profit. It has to be emphasized that in the model under analysis an enterprise can set higher price and expect to earn higher profit than its competitor if its production is more differentiated: for example, if the $1^{\text {st }}$ company's production is more differentiated than its rival's, then $b_{1}<b_{2}$ (in other words, the positive impact of the $1^{\text {st }}$ company's price increase to the individual demand of the $2^{\text {nd }}$ company falls short to the growth of the $1^{\text {st }}$ company's demand due to the similar price increase by the $2^{\text {nd }}$ producer) and, accordingly, $p_{1}^{*}>p_{2}^{*}$ and $\pi_{1}^{*}>\pi_{2}^{*}$. So, while a short-term goal of an enterprise, acting under differentiated Bertrand, could be an appropriate price setting; long-term decisions should aim at increasing production differentiation. One of the best ways to deeper differentiate production is through research and innovation - a market player, able to produce and implement the certain innovation earlier and more effectively than his actual or potential rivals, achieves the competitive advantage (Melnikas 2001).

Moving further, it is passed over to analyzing a twostage price setting game in a differentiated duopoly market. Similar to Stackelberg model, the solution starts from the follower's profit maximization:

$$
p_{2}^{f}\left(p_{1}\right)=\frac{1}{2}\left(A+b_{1} p_{1}\right),
$$

which is the $2^{\text {nd }}$ company's reaction function (index $f$ means the price follower, $l$ - the price leader). Then, the mathematical expression of the $1^{\text {st }}$ enterprise's (the leader's) profit is:

$$
\pi_{1}\left(p_{1}, p_{2}^{f}\left(p_{1}\right)\right)=p_{1}\left(A-p_{1}+b_{2} \cdot \frac{1}{2}\left(A+b_{1} p_{1}\right)\right) .
$$

The leader's and the follower's prices are:

$$
p_{1}^{l}=\frac{A\left(2+b_{2}\right)}{2\left(2-b_{1} b_{2}\right)} ; p_{2}^{f}=\frac{A\left(4-b_{1} b_{2}+2 b_{1}\right)}{4\left(2-b_{1} b_{2}\right)} ;
$$

and the profit expressions are:

$\pi_{1}^{l}\left(p_{1}^{l}, p_{2}^{f}\right)=p_{1}^{l}\left(A-p_{1}^{l}+b_{2} p_{2}^{f}\right)=\frac{A^{2}\left(2+b_{2}\right)^{2}}{8\left(2-b_{1} b_{2}\right)} ;$

$\pi_{2}^{f}\left(p_{1}^{l}, p_{2}^{f}\right)=p_{2}^{f}\left(A-p_{2}^{f}+b_{1} p_{1}^{l}\right)=\frac{A^{2}\left(4-b_{1} b_{2}+2 b_{1}\right)^{2}}{16\left(2-b_{1} b_{2}\right)^{2}}$.

From the first look the latter mathematical expressions do not allow comparing profits of the leader and the follower. Apparently, similar to the simultaneous game, the profit of each company depends on its product differentiation - the more differentiated production is, the higher profit could be expected. In case the products are differentiated equally $\left(b_{1}=b_{2}\right)$, the follower's profit would always exceed the leader's. Besides, it has to be highlighted, that in the described case the follower receives higher profit than in the simultaneous game. So, unlike Stackelberg equilibrium, in the analyzed differentiated Bertrand enterprises have the second mover advantage, that is the companies should avoid announcing their prices before the competitor does.

Having analyzed Stackelberg and differentiated Bertrand dynamic games with the help of game theory, it has to be concluded that the first move does not always lead to competitive advantage. The calculations prove that the first mover advantage appears in Stackelberg competition (the slope of reaction curves is negative); while the second move grants advantage in differentiated Bertrand (the best response functions are positively sloped). A. Rabah and A. Stepanova (2002) formulated this principle a bit more accurately proving that if both reaction curves in a duopoly market have positive slopes, at least one company has the second mover advantage; when both curves are negatively sloped - both enterprises have the first mover advantage; in a mixed case a player with the negative reaction function slope has the first mover advantage. J. Bulow, J. Geanakoplos and P. Klemperer, who analyze the first and the second mover advantage in oligopoly, distinguish two strategy groups: strategic substitutes (negative reaction function slope) and strategic complements (positive reaction function slope) (Rasmusen 2006).

\section{The application of game theory to support cartel stability}

In section 3 of the paper it has been proved mathematically that an outcome of a static Cournot game could never be a cartel agreement. However, such statement may sound a bit drastic and facile - surely, it contradicts the natural will of market players to seek for profit maximization and definitely would not correspond to widely spread practice of cartel agreements in the real world. So, coming back to Cournot competition model, it is argued, what the equilibrium would be, or in other words - could the Pareto efficient outcome be achieved - if the described Cournot game was repeated several times. The current section of the article is devoted to equilibrium estimation in repeated games dynamic games, in which players repeatedly make the same decisions (from the same action set) in the same environment.

Suppose, a game is repeated 10 times. Is any outcome, different from Cournot-Nash, possible at least in one of 
the games? A classic of game theory R. Selten proposes to start analyzing a supergame from the last game. The outcome of the very last game would not differ from a static game because neither player would tend to follow the cartel agreement (see the cheater's game in section 3). Then, as both companies expect their rival to choose Cournot in the last game, in the last but one game it is not worth keeping the reputation of a fair cartel player either. So, in the last but one game, and accordingly, in all the previous games both companies would choose Cournot outputs. This result is called the "Chain-store Paradox", which is, according to Selten (R. Selten demonstrated the following paradoxical result: if we assume that the exact number of potential competitors is the matter of common belief, then it is irrational for the monopolist ever to engage in predatory behaviour (Koons 1992)), valid for finite repeated games.

However, the Pareto efficient outcome is still achievable in repeated games, whereas the following conditions are satisfied (also called "The Folk Theorem" conditions):

1) the probability that the game ends at any repetition is zero, or positive and sufficiently small;

2) the rate of time preference is zero, or positive and sufficiently small;

3) there is an effective punishment for the player deviating from Pareto.

Assume the Cournot game, described in section 3, is repeated and infinite or at least considered to be infinite (which seems to be better corresponding to real life than the term of infinity). The players form a cartel on condition that, in case one of them deviated in the game $i$, the agreement would be called off from the game $i+1$. The Pareto efficient payoffs would be (with $(a-c)^{2}$ being equalled to 1$)$ :

$$
\pi_{1 M}=\pi_{2 M}=\frac{1}{8}+\frac{1}{1+r} \cdot \frac{1}{8}+\frac{1}{(1+r)^{2}} \cdot \frac{1}{8}+\ldots=\frac{1}{8}+\frac{1}{8 r},
$$

where $r$ - the market interest rate.

The cheater, who deviated from Pareto quantity in the game $i$, would earn (present value in the period $i$ ):

$$
\pi_{s}^{i}=\frac{9}{64}+\frac{1}{1+r} \cdot \frac{1}{9}+\frac{1}{(1+r)^{2}} \cdot \frac{1}{9}+\ldots=\frac{9}{64}+\frac{1}{9 r} .
$$

Then the cheating condition would be:

$$
\frac{9}{64}+\frac{1}{9 r}>\frac{1}{8}+\frac{1}{8 r} \Rightarrow r>\frac{8}{9}
$$

- that is, if the interest rate exceeded $88.8 \%$, the cartel agreement would break up. For the rate being under this limit, a grim punishment strategy once deviated always play Cournot maintains the cartel agreement and guarantees the maximum profit.

There are several strategies to punish a deviant, such as: Tit-for-Tat, Minimax, Maximin etc. Any of them, to be successfully used in a repeated infinite game, has to be credible (the $3^{\text {rd }}$ condition), that is the present value of the payoff with the punishment applied should be less than the present value of Pareto payoff.

Coming back to the $1^{\text {st }}$ condition, assume, there is a probability $\rho$ that the game ends at the next stage, with the market interest rate, for the purpose of simplicity, being equal to zero. Pareto outcome payoffs, the cheater's payoff and the cheating condition would be:

$$
\begin{aligned}
& \pi_{1 M}=\pi_{2 M}=\frac{1}{8}+\rho \cdot \frac{1}{8}+\rho^{2} \cdot \frac{1}{8}+\ldots=\frac{1}{8}+\frac{1}{8} \cdot \frac{\rho}{1-\rho} ; \\
& \pi_{s}=\frac{9}{64}+\rho \cdot \frac{1}{9}+\rho^{2} \cdot \frac{1}{9}+\ldots=\frac{9}{64}+\frac{1}{9} \cdot \frac{\rho}{1-\rho} \\
& \frac{9}{64}+\frac{1}{9} \cdot \frac{\rho}{1-\rho}>\frac{1}{8}+\frac{1}{8} \cdot \frac{\rho}{1-\rho} \Rightarrow \rho<\frac{9}{17} .
\end{aligned}
$$

- in case the probability that the supergame ends in the next game does not exceed $\sim 52.94 \%$, with a grim punishment strategy applied, the players would not benefit from cheating. This result provides a more practical interpretation of a purely theoretical condition of an infinite game: it is well enough having sufficient, independent from game number, probability that the next game would take place for a cartel agreement to be sustainable (sure, with respect to conditions 2 and 3 ). Theoretical circumstances of cartel breakdowns are usually related to economic cycles: during an economic recession or depression due to diminishing demand producers ought to reduce prices below collusive; or during an economic boom, with a rapid increase in demand, it is more profitable to reduce price than to keep it at a cartel level. V. Suslow's empiric study shows that cartels tend to collapse during economic downturn more often (Carlton, Perloff 2005). However, having more or less steady economic situation, following a cartel agreement should be natural behaviour of a profit maximizing enterprise, and this conclusion is supported by the mathematical calculations above.

\section{The comparative analysis of duopoly models practical application}

Discussing possible equilibriums of oligopoly models, E. Chamberlin says that equilibrium strongly depends on the assumptions made. Monopoly outcome is possible if each producer tends to maximize his own profit with regard to his own impact, both direct and indirect, 
on the current situation in the market. Competitive outcome appears when producers ignore their indirect impact on market price, each thinking that others would not be affected by his actions. The most expected outcome lies between these two extremes when the interaction is recognized and stability is being affected by a degree of uncertainty (Skinner, Chamberlin 2001).

Classic duopoly models usually depend on numerous assumptions, which correspondence to the real world is at least doubtful. Cournot model is criticised for several aspects mentioned below (Jacobson, AndreossoO`Callaghan 1996).

First, under Cournot quantity setting strategies of each player are independent from each other: with the $1^{\text {st }}$ company's output changing according to its strategy, the $2^{\text {nd }}$ company's quantity setting strategy remains constant. The question, to what extent enterprises tend to react to rivals' actions, and Bertrand's critics of the mentioned Cournot model's assumption, gave birth to the conjectural variation concept $(\mathrm{K}$. Cowling and M. Waterson are among the first to apply it in 1976). The concept was influenced by P. Sweezy's kinked demand curve duopoly model (designed in 1939), where a duopolist expects that his competitor would immediately react to a price cut (by reducing his price as well), while an increase in price would not give rise to any responsive actions from the competitor. Sweezy's model explains price stability in duopoly (in equilibrium), but it has little to say about the process of reaching the equilibrium.

Second, Cournot in his classic duopoly model shows, as well as it has been proved in this paper (see section 3 ), that duopoly enterprises, by forming a cartel, could expect higher profits than competing with each other. However, according to mathematics of game theory, a cartel agreement would not be equilibrium in a static game, and each company would tend to deviate from the output agreed. Bertrand's critics of this conclusion of Cournot model is based on the profit maximizing rational behaviour assumption, because maintaining a cartel is in self-interest of each company.

Finally, the main doubt about Cournot model concerns the question, how often oligopoly enterprises compete by choosing quantities, not prices. Bertrand criticised Cournot, arguing that the latter was wrong by choosing a quantity variable. In Bertrand's opinion, price is the only appropriate variable, and such opinion has been dominant among economists for many years (Friedman 1999). J. Friedman, with the help of mathematical methods, analyzed 3 differentiated product static oligopoly models: a simultaneous price and quantity setting, and a pair of two-stage models where variables were set in the following order: quantities, then prices; and prices, followed by quantities. The scientist makes the conclusion that equilibrium does not exist in the first model; in the second one equilibrium exists only in special cases and it coincides with quantity setting equilibrium; while in the third model equilibrium always exists and coincides with price setting model equilibrium. So, according to Friedman (1988), the choice of price as the main variable in oligopoly models seems to be more solid and adequate. The opinion of the latter scientist is supported by a majority of company managers, who have taken part in the survey held by K. Aiginger (1999): 61.7\% of respondents confirmed their choice of price as a competitive variable, while only $38.3 \%$ chose quantities.

The classic Bertrand price competition model is criticised mainly due to its result: it could hardly happen in practice that two companies only, interacting in a duopoly market, finally set prices equal to their marginal costs (pure competition prices). From this point of view, the results of Cournot model are logical and more admissible: having the number of competitors less than in pure competition but more than one (enterprises experience market power but not monopolistic), prices are set higher than in pure competition but lower than monopolistic; quantities sold in the market are between monopolistic and competitive; growing number of competitors reduces market power, thus cutting the price that converges to competitive.

It has to be emphasized that practical application of both Cournot and classic Bertrand models requires the fulfilment of some crucial assumptions, first of all homogenous products. Even the product of the classic Cournot model - mineral water - in the real world is used to be sold in different packing, at a grocery store or in a restaurant, with the help of commercials, etc.

From the practical point of view (correspondence to reality), in the author's opinion, differentiated Bertrand model seems to be the strongest (see the summary of the comparative analysis of the duopoly models in Table 4). It does not require a controversial product homogeneity assumption, enterprises compete by setting prices (in practice it is more likely than quantity competition), companies tend to invest in deeper product differentiation (improve quality, create brand names, promote consumer loyalty), thus reducing elasticity of individual demand and increasing entrance barriers. Product differentiation created market entrance barriers, let incumbents possess market power and, accordingly, raise prices over marginal costs and gain economic profit. An attempt to increase profit encourages 
Table 4. The summary of the comparative analysis of the duopoly models

\begin{tabular}{|c|c|c|}
\hline Model & Advantages & Disadvantages \\
\hline Cournot & $\begin{array}{l}\text { 1. Logical results: prices and quantities between } \\
\text { monopolistic and competitive; market power } \\
\text { diminishes as the number of competitors } \\
\text { grows; the first mover advantage. } \\
\text { 2. Stability of Nash equilibrium. } \\
\text { 3. Supports cartel stability in repeated games } \\
\text { with predictable future. }\end{array}$ & $\begin{array}{l}\text { 1. Product homogeneity assumption. } \\
\text { 2. Strategies of duopolists are independent from } \\
\text { each other. } \\
\text { 3. Quantity variable. }\end{array}$ \\
\hline $\begin{array}{l}\text { Classic } \\
\text { Bertrand }\end{array}$ & 1. Price variable. & $\begin{array}{l}\text { 1. Product homogeneity assumption, horizontal } \\
\text { individual demand curve. } \\
\text { 2. Doubtful result: competitive outcome with only } \\
\text { two players in a market. }\end{array}$ \\
\hline $\begin{array}{l}\text { Differentiated } \\
\text { Bertrand }\end{array}$ & $\begin{array}{l}\text { 1. Price variable. } \\
\text { 2. Differentiated production, non-zero sloped } \\
\text { individual demand. } \\
\text { 3. Stability of Nash equilibrium. } \\
\text { 4. Logical results: prices and quantities are } \\
\text { between monopolistic and competitive; profit } \\
\text { depends on product differentiation level. }\end{array}$ & 1. Doubtful result: the second mover advantage. \\
\hline
\end{tabular}

companies to support research and development measures which lead not only to lower costs, but improve production quality as well. Price-quantity combinations in differentiated Bertrand are between monopolistic and competitive - logical and admissible result.

To summarize the comparative analysis of theoretical models produced in this section, it has to be emphasized once again that application of any theoretical model concerns many special conditions and assumptions. The application of different duopoly models to the same situation in the market may lead to diametrically opposite results: from competitive price and consumer efficient quantity in classic Bertrand to monopolistic price and production level in Cournot cartel. The spectrum of possible results may be supported mathematically (the following has been done in the article), but the main problem of practical application of game theory is associated with the choice of exact model to analyze the exact market situation together with numerous assumptions of each model, making the theoretical results stay far from practical evidence.

\section{Conclusions}

The paper briefly describes the main game theory models applied for duopoly market analysis. The models, accompanied by non-complicated mathematics, were applied to hypothetic situations in a market, helping to estimate duopoly market equilibrium, evaluate equilibrium payoffs (economic profits) for each player, judge on efficiency and stability of equilibrium.
According to the analysis of duopoly models, it has to be noted that application of game theory to duopoly markets is adequate and grounded due to the following reasons:

1) game theory helps to highlight the importance of strategic interaction of enterprises in duopoly markets;

2) game theory helps to support mathematically the special features of companies' behaviour in duopoly markets: competing versus forming and maintaining cartels, the first and the second mover advantage, initiatives to deepen product differentiation;

3) game theory draws the relationship between the chosen strategy and performance, allows to compare estimated results of different enterprises.

Nevertheless the arguments above sound in favour of game theory, its practical application remains doubtful because of the following major remarks:

1) multiplicity of models together with having no reliable criteria to identify the certain model game being played. Choosing one or another model to analyze the same market situation may lead to absolutely different results;

2) the certain assumptions, applied to game theory models, are hardly met in the real world - that may cause major deviations between theoretical and practical results;

3) in the hypothetic situations, analyzed throughout the article, prices and quantities were the only variables to be estimated. In practice it is rather problematic at least approximately estimate the market 
demand, company's individual demand and even more complicated to draw up competitor's individual demand. So, in reality the number of unknown variables could be much larger, making the application of the certain model more complicated and increasing the possible errors of the results.

Summarizing the analysis of application of game theory models to duopoly markets and having regard to the highlighted weaknesses of such application, it should be stated that there are certain doubts about the ability of analyzed models to estimate prices and quantities with sufficient accuracy. Nevertheless, theoretical models could help to support the specific features of enterprise interaction in duopoly and define the guidelines of their behaviour, as well as the main strategic directions (for example: forming a cartel, price decrease in reaction to competitor's price cut, announcement of foreseen production level, etc.). Practical application of game theory is rather limited - in order to get more accurate results, the application of theoretical models should be reasonable, coherent and careful, combined with strategic management, industrial organization and other sciences, as well as with economic logic.

\section{References}

Aiginger, K. 1999. The use of game theoretical models for empirical industrial organization, in Competition, Efficiency and Welfare - Essays in Honor of Manfred Neumann, Dordrecht, Kluwer Academic Publishers, 253-277.

Carlton, D. W.; Perloff, J. M. 2005. Modern Industrial Organization. Fourth Edition. Berkeley, University of California. 822 p.

Friedman, J. W. 1988. On the strategic importance of prices versus quantities, Journal of Economics 19(4): 607-622.

Friedman, J. W. 1999. The legacy of Augustin Cournot. Department of Economics Working Paper 99-05, University of North Carolina.
Jackson, M. O.; Wilkie, S. 2000. Endogenous games and mechanisms: side payments among players [online], in EconPapers [cited 20 November 2007]. Available from Internet: < http://econpapers.repec.org/paper/wpawuwpmi /0211008.htm>.

Jacobson, D.; Andreosso-O`Callaghan, B. 1996. Industrial Economics and Organization. A European Perspective. London: McGraw-Hill Publishing Company. 367 p.

Koons, R. C. 1992. Doxastic paradox and reputation in iterated games, in Proceedings of the $4^{\text {th }}$ conference on Theoretical Aspects of Reasoning about Knowledge, Monterey, California. San Francisco: Morgan Kaufmann Publishers, 60-72. ISBN 1-55860-243-9.

Melnikas, B. 2001. Verslo efektyvumas, konkurencija ir inovacijos Rytų ir Vidurio Europos šalyse: globalizacijos ir Europos integracijos aspektai [Business efficiency, competition and innovation in the East and Central European countries: aspects of globalization and European integration], Verslas: teorija ir praktika [Business: Theory and Practice] 1(2): 107-120.

Ponikvar, N; Rant, M. 2007. Firm specific determinants of markup - the case of Slovenian manufacturing firms, Journal of Business Economics and Management 8(3): 203-212.

Rabah, A.; Stepanova, A. 2002. Second-Mover Advantage and Price Leadership in Bertrand Duopoly [online] [cited 17 November 2007]. Available from Internet: <http://www. cerge-ei.cz/pdf/events/papers/040330_t.pdf $>$.

Rasmusen, E. 2006. Games and Information. An Introduction to Game Theory. Fourth Edition. Oxford: Blackwell Publishers. 484 p. ISBN 978-1-4051-3666-2.

Saloner, G.; Shepard, A.; Podolny, J. 2001. Strategic Management. New York: John Wiley \& Sons, Inc., 442. ISBN 0-471-38071-7.

Skinner, A.; Chamberlin, E. H. 2001. Oligopoly and oligopolistic interdependence: the issue of space, in Economics Broadly Considered: Essays in Honor of Warren J. Samuels, 105-124.

Von Neumann, J.; Morgenstern, O. 1953. Theory of Games and Economic Behavior. Third Edition. London: Oxford University Press. 641 p. 